\section{En bloc excision of intraocular epithelial cystic downgrowth using syngeneic auricular cartilage}

\begin{abstract}
Aim To describe the surgical management of epithelial cystic downgrowth by en bloc excision and use of syngeneic auricular cartilage in two children.

Study Design Retrospective interventional case series.

Method The charts of two patients treated for epithelial cystic downgrowth with en bloc excision and auricular cartilage transplant were reviewed. Details of ocular history, preoperative and postoperative visual acuity, intraocular pressure, ocular examination findings, surgical procedure and subsequent management were noted.
\end{abstract}

Results Two children aged 4 and 6 years, with epithelial cysts who underwent en bloc excision were identified. The cysts had developed following penetrating eye injury. Surgery involved en bloc resection of the cyst and associated tissue, and replacement of the excised corneoscleral tissue with syngeneic auricular cartilage. One patient additionally required synechiolysis, discission of a secondary cataract and anterior vitrectomy. In both cases, the epithelial tissue was successfully removed and the auricular cartilage transplant was well-apposed. Visual acuity remained at the preoperative level in the first patient due to amblyopia; in the second patient visual acuity improved to $6 / 7.5$ with mild astigmatic correction.

Conclusion En bloc excision provides the most definitive surgical treatment of cystic epithelial downgrowth. Auricular cartilage may be used for sclerokeratoplasty when donor cornea or sclera is unavailable.

Eye (2005) 19,97-100. doi:10.1038/sj.eye.6701483

Published online 30 July 2004
A Ganesh, N Al-Fadhil, U Wali and AA Bialasiewicz

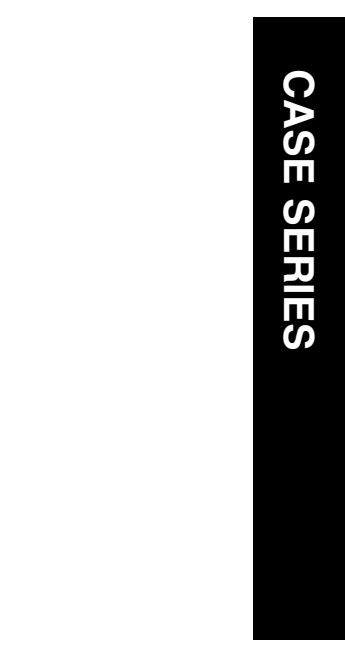

Keywords: auricular cartilage; epithelial

downgrowth; en bloc excision;

sclerokeratoplasty

Intraocular epithelial cysts are caused by invasion of epithelium into the anterior chamber through an inadequately apposed corneal or scleral defect. They may also develop when epithelial cells are introduced into the anterior chamber at the time of penetrating injury. In the anterior chamber, the epithelium grows sheet-like across ocular structures, or forms a cyst. Epithelial cysts can remain dormant for many years. Small, stable, and asymptomatic cysts may therefore be observed. Treatment is indicated if the cyst is growing to prevent or treat iridocyclitis, secondary glaucoma, or loss of vision. Numerous surgical approaches to the management of epithelial cysts have been reported, including cryotherapy, ${ }^{1}$ photocoagulation, ${ }^{2}$ and excision. ${ }^{3}$

En bloc excision of paracentral cystic epithelial downgrowth into the anterior chamber provides the most definitive and curative surgical treatment of this condition. ${ }^{4-6}$ This requires the use of donor cornea, which may not be available in many parts of the world. We report on the successful alternative of implanting custommade syngeneic auricular cartilage for sclerokeratoplasty to manage intraocular epithelial cysts.

\section{Case Reports}

Case 1

A 5-year-old boy sustained a penetrating cornea-iris-lens injury with a knife in his left eye, and underwent wound repair and lens extraction at a local hospital. This was followed 3 months later by a secondary posterior chamber intraocular lens implantation.
Department of

Ophthalmology Sultan

Qaboos University Hospital Oman

Correspondence: A Ganesh Department of Ophthalmology Sultan Qaboos University Hospital 123

Al Khod/Muscat, Oman Tel: 968-513355ext3516 Fax: 968-514100

E-mail: ganeshs@ omantel.net.om

Received: 22 April 2003 Accepted: 6 November 2003

Published online: 30 July 2004 
Postoperatively he developed an 'iris cyst', intraocular lens dislocation, and a secondary cataract, and was referred to us.

At presentation, the child had photophobia, left exotropia (20 p.d. Krimsky), and a best-corrected visual acuity of OD 6/6 and OS 6/120. Intraocular pressure was OU: $18 \mathrm{mmHg}$. The ocular examination of the right eye was unremarkable. The left eye had a corneal scar extending from the limbus at 9-11 O'clock. A partial anterior chamber angle closure from 9-11 O'clock due to the epithelial cystic downgrowth originating from the corneal penetration was observed. The iris was impressed by the mass, resulting in pupillary distortion. Posterior synechiae, intraocular lens displacement into the anterior chamber, and a secondary cataract were also present (Figure 1a). Fundus details could not be
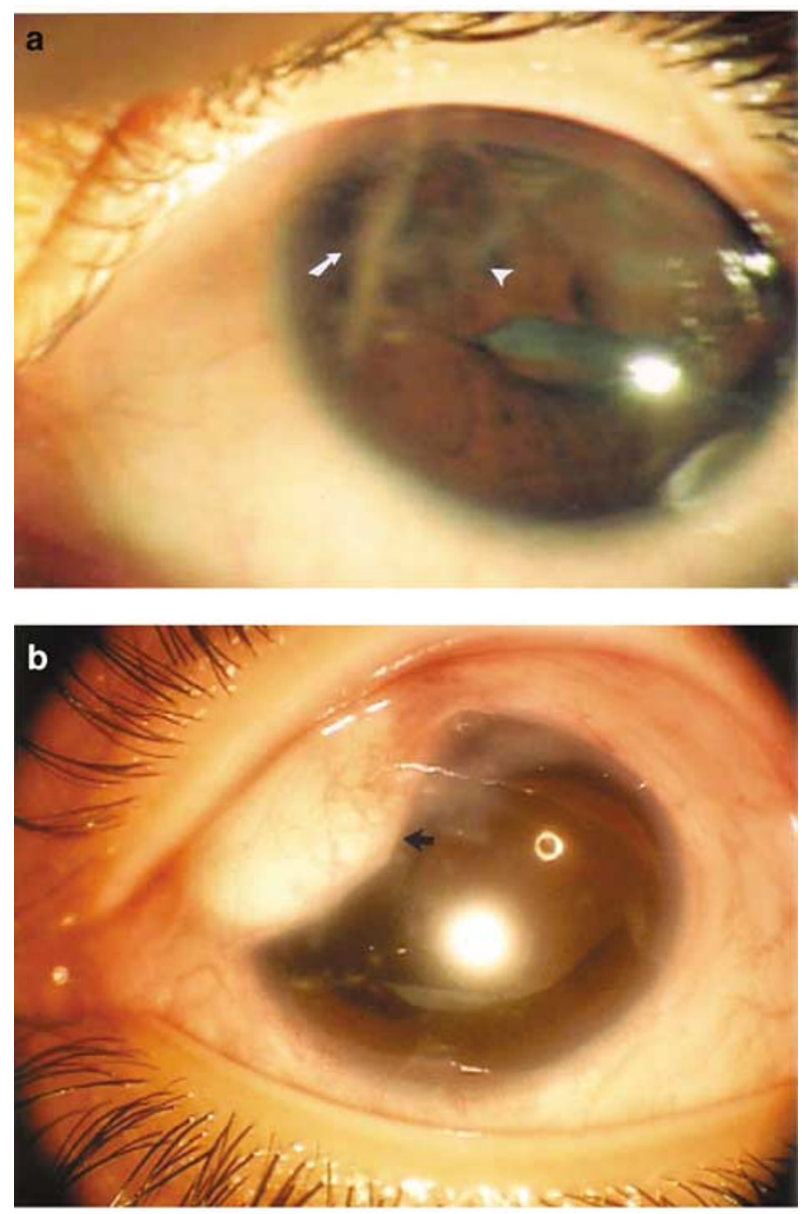

Figure 1 (a) Case 1: Diffuse slit lamp photograph of the anterior segment OS, showing corneal scarring (arrow), pupillary distortion, iris cyst (arrowhead), and secondary cataract. (b) Postoperative photograph of the anterior segment OS (5 months after surgery) showing a well-apposed graft (arrow). visualized; B-scan ultrasonography revealed an unremarkable posterior segment.

At surgery, the corneal lesion was demarcated with a $7.3 \mathrm{~mm}$ trephine. Penetrating trephination of the cornea and lamellar excision of the sclera was carried out. Excision of the iris cyst en bloc, synechiolysis, discission of the secondary cataract, and anterior vitrectomy were performed.

The auricular cartilage graft was prepared applying two haemostats to the margin of the right ear to evert the ear and facilitate an approach to its posterior surface. After marking the incision along the mid-portion of the pinna, a no. 15 Bard-Parker blade was used to incise the skin and underlying subcutaneous tissue. The overlying tissue was separated from the auricular cartilage with blunt dissection using Wescott scissors. The required size of graft was measured, a small incision was made through the cartilage with the no. 15 blade, and lamellar dissection of the cartilage was completed using Wescott scissors. The wound was then closed with interrupted 40 nylon sutures.

After customizing the graft to a size of $7.2 \mathrm{~mm}$ diameter $\times 0.4 \mathrm{~mm}$ thickness, a 10-0 ethilon GS 12 running suture was used for fixation of the graft to the cornea, and 7-0 vicryl interrupted sutures for fixation to the sclera. The cartilage was covered with conjunctiva on the scleral side. Anterior chamber depth was maintained with viscoelastic.

Postoperatively, prednisolone acetate drops $\mathrm{q} 2 \mathrm{~h}$ and gentamicin $0.3 \%$ drops q.i.d. were commenced. Sutures were removed after 8 weeks. Refraction showed a mild hypermetropic astigmatism $\left(+2.0 /\right.$ is $\left.-2.0 / 90^{\circ}\right)$.

Spectacle correction and patching of the right eye for $6 \mathrm{~h}$ per day was advised.

Histopathological evaluation of the excised tissue confirmed the diagnosis of an epithelial cyst. At 5 months postoperatively the best-corrected visual acuity remained at OS $+2.0 /-2.0 / 90^{\circ}=6 / 120$. The graft was wellapposed and vascularized in the periphery, leaving the visual axis clear (Figure 1b). The anterior chamber was deep and quiet, pupil central, intraocular lens in situ, and the intraocular pressure at $20 \mathrm{mmHg}$. Fundus examination revealed a normal disc, macula, and periphery. The patient was advised to continue using the refractive correction (polycarbonate lenses) and maintenance occlusion of the left eye for $1 \mathrm{~h}$ per day.

\section{Case 2}

A 6-year-old boy sustained a penetrating corneal injury with a bird beak in his right eye, and was advised wound repair. The parents refused surgery. After 6 months he presented with photophobia and visual impairment. 
Ocular examination revealed a best-corrected visual acuity of OD 6/18 and OS 6/6. Intraocular pressure was OD $10 \mathrm{mmHg}$ and OS $16 \mathrm{mmHg}$. The left eye was unremarkable. In the right eye, a corneal scar was seen at the limbus at the $2 \mathrm{O}^{\prime}$ clock position, with an epithelial cyst emanating from the wound site and obstructing the visual axis (Figure 2a). Examination of the anterior chamber revealed a $2+$ flare and $1+$ cells. The lens was clear and normal in position. Fundoscopy revealed an unremarkable posterior segment.

At surgery, after peritomy, the cornea and iris cyst were excised en bloc and a lamellar dissection of the sclera $\left(7.5 \times 4.52 \mathrm{~mm}^{2}\right)$ was performed.

Auricular cartilage from the right ear was harvested and fixed with interrupted sutures, as described previously in case 1 .

Histopathological examination of the tissue confirmed the clinical diagnosis of an epithelial cyst. Six months
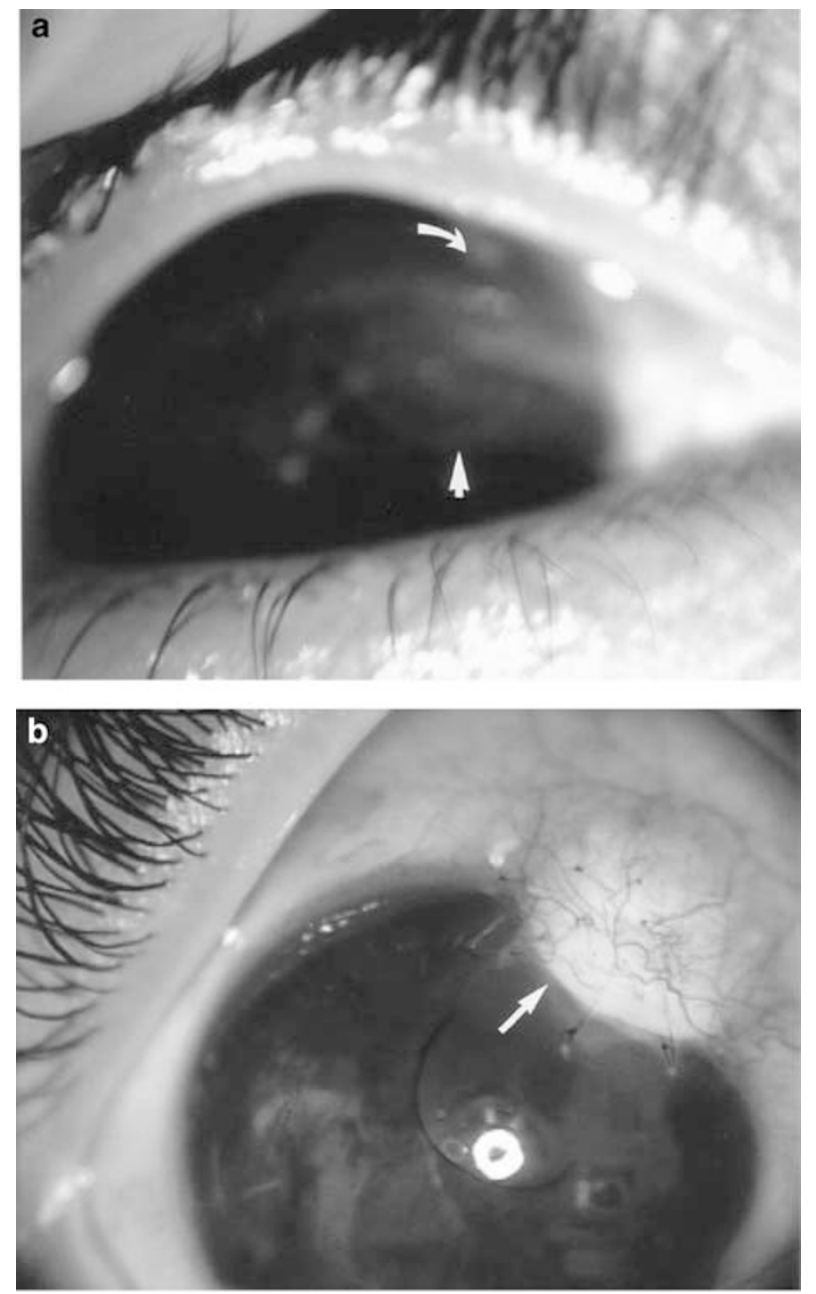

Figure 2 (a) Case 2: Preoperative photograph of the anterior segment showing the corneal scar (arrow) and epithelial cyst (arrowhead). (b) Postoperative photograph (1 month after surgery) showing a well-apposed graft (arrow). postoperatively the best-corrected visual acuity was $\mathrm{OD}+1.75 /-4.5 / 45^{\circ}=6 / 7.5$, and the graft appeared well-apposed (Figure 2b).

\section{Comment}

The management of eccentric corneoscleral lesions may necessitate a tectonic sclerokeratoplasty, which serves to maintain structural and functional integrity of the globe, and also helps to prevent a recurrence of the primary disease. $^{7}$

En bloc excision of epithelial cysts using a tectonic sclerokeratoplasty provides the most definitive treatment for cystic epithelial downgrowth. ${ }^{5,6}$ Haller et al ${ }^{8}$ reviewed surgical approaches to the management of epithelial cysts and concluded that epithelial cysts could be managed conservatively with aspiration and endophotocoagulation, with good results. They recommended this strategy particularly in children, in whom preservation of ocular structures might facilitate amblyopia management. However, other authors have stated that laser puncture, simple aspiration, or subtotal excision may convert an epithelial cyst into epithelial sheets or downgrowth, making it a more difficult management issue. ${ }^{9}$

In our patients, we adopted a more aggressive approach with en bloc excision of the cyst, iris, and cornea. Lack of donor material necessitated the use of auricular cartilage to replace diseased tissue. Auricular cartilage grafting has been successfully performed for eyelid reconstruction, ${ }^{10}$ repair of orbital floor defects, ${ }^{11}$ rhinoplasty, ${ }^{12}$ laryngotracheal reconstruction, ${ }^{13}$ as well as temporomandibular joint repair. ${ }^{14}$ The advantages of an autologous auricular cartilage graft are ease of harvesting, lack of antigenicity (a common problem with allogeneic cadaveric transplants), low nutritional requirement, and ability to retain bulk. ${ }^{15}$ The acceptance of cartilage as a syngeneic graft in the corneoscleral region may have a biochemical basis, viz. similarity of collagen type I in both tissues: the cornea and elastic cartilage.

Many modifications in sclerokeratoplasty, including lamellar scleral dissection, well above the scleral spur, have been employed to maintain the anterior chamber angle, preserve trabecular meshwork function, and avoid postoperative glaucoma. ${ }^{16-18}$ The most important vision-limiting factor in eccentric tectonic sclerokeratoplasty is corneal astigmatism. ${ }^{4}$ We attribute the low level of corneal astigmatism seen in our patients to a meticulous placement of graft tissue and suturing technique. It is also possible that the flexibility of elastic tissue in the cartilaginous graft permits it to be 
stretched, with a resultant minimal distortion of host tissue.

To our knowledge, this is the first report on the use of auricular cartilage for sclerokeratoplasty after en bloc excision of epithelial inclusion cysts of the anterior chamber.

\section{References}

1 Ferry AP, Naghdi MR. Cryosurgical removal of epithelial cyst of iris and anterior chamber. Arch Ophthalmol 1967; 77: 86-87.

2 Scholz RT, Kelley JS. Argon laser photocoagulation treatment of iris cysts following penetrating keratoplasty. Arch Ophthalmol 1982; 100: 926-927.

3 Sugar HS. Resection of the cornea for epithelial implantation cyst of the anterior chamber. Am J Ophthalmol 1962; 54: 800-803.

4 Bialasiewicz AA, Förster W, Busse H. Visual rehabilitation by tectonic reconstruction of the anterior segment. Klin $\mathrm{Mbl}$ Augenheilkd 1993; 203: 240-246.

5 Forster RK. Corneoscleral block excision of postoperative anterior chamber cysts. Trans Am Ophthalmol Soc 1995; 93 83-97.

6 Naumann GO, Rummelt V. Block excision of cystic and diffuse epithelial ingrowth of the anterior chamber. Report on 32 consecutive patients. Arch Ophthalmol 1992; 110: 223-227.

7 Hassenstein A, Bialasiewicz AA, von Domarus D, Schäfer HJ, Richard G. Tapioca melanomas of the iris: block excision, immunohistology and report on two cases. Graefes Arch Clin Exp Ophthalmol 1999; 237: 424-428.
8 Haller JA, Stark WJ, Azab A, Thomsen RW, Gottsch JD. Surgical approaches to the management of epithelial cysts. Trans Am Ophthalmol Soc 2002; 100: 79-84.

9 Groh MJ, Nguyen NX, Kuchle M, Naumann GO. Transformation of cystic into diffuse epithelial ingrowth caused by laser-puncture. Report on four patients. Klin Monatsbl Augenheilkd 2002; 219: 37-39.

10 Yaqub A, Leatherbarrow B. The use of autogenous auricular cartilage in the management of upper eyelid entropion. Eye 1997; 11: 801-805.

11 Hendler BH, Gataeno J, Smith BM. Use of auricular cartilage in the repair of orbital floor defects. Oral Surg Oral Med Oral Pathol 1992; 74: 719-722.

12 Nakakita N, Sezaki K, Yamazaki Y, Uchinuma E. Augmentation rhinoplasty using an L-shaped auricular cartilage framework combined with dermal fat graft for cleft lip nose. Aesthetic Plast Surg 1999; 23: 107-112.

13 Silva AB, Lusk RP, Muntz HR. Update on the use of auricular cartilage in laryngotracheal reconstruction. Ann Otol Rhinol Laryngol 2000; 109: 343-347.

14 Tucker MR, Spagnoli DB. Autogenous dermal and auricular cartilage grafts for temporomandibular joint repair. Atlas Oral Maxillofac Surg Clin North Am 1996; 4: 75-92.

15 Zalzal GH, Cotton RT, McAdams AJ. Cartilage grafts present status. Head Neck Surg 1986; 8: 363-367.

16 Taylor DM, Stern AL. Reconstructive keratoplasty in the management of conditions leading to corneal destruction. Ophthalmology 1980; 87: 892-896.

17 Cobo M, Oritz JR, Safran SG. Sclerokeratoplasty with maintenance of the angle. Am J Ophthalmol 1992; 113: 533-537.

18 VÖlcker HE, Naumann GO. Eccentric tectonic minikeratoplasty in corneal, corneoscleral and scleral processes. Klin Monatsbl Augenheilkd 1984; 185: 158-166. 